\title{
Substituted judgment, procreative beneficence, and the Ashley treatment
}

\section{PHILLIPS AND WENDLER ON SUBSTITUTED JUDGMENT}

It is commonly thought that when a patient is unable to make a treatment decision for herself, patient autonomy should be respected by consulting the views of a patient surrogate, normally either the next-of-kin or a person previously designated by the patient.

On one view, the task of this surrogate is to make the treatment decision that the patient would have made if competent. But this so-called 'substituted judgment standard' (SJS) has come in for has come in for a good deal of criticism recently. For instance, some question whether surrogates are able to reliably predict what the patient would have chosen. Others wonder how respecting a patient's counter-factual, rather than actual, choices is supposed to respect her autonomy. Such concerns have lead some to reject the SJS and argue for alternative characterisations of the role of surrogate decision-makers.

In their feature article, John Phillips and David Wendler argue that the SJS does not need be rejected, but merely re-interpreted. On their favoured 'endorsed life' interpretation, surrogates ought to choose the treatment option that 'best promotes the course of life that the patient valued'. ${ }^{1}$ This, they note, will often be the course of action that the patient would have chosen, but this will not always be so: in some cases, the patient would have irrationally chosen a treatment that in fact undermines the course of life he values.

\section{WHICH PAST VALUES MATTER?}

Four commentaries raise a number of objections to Phillips and Wendler's suggestion. However, one aspect of their proposal that escapes criticism is their view about which past values matter. They suggest that surrogates should make the treatment decision that best promotes the values of the patient's most recent competent self; the values the patient held just before becoming incompetent.

This view strikes me as intuitively plausible, but it is difficult to explain why it should be accepted. The thought underpinning the endorsed life approach is that we can respect an incompetent person's autonomy by ensuring that his life is governed by his own values. But why give precedence to the patients last past values rather than, say, taking into account all values that the patient sincerely held during the course of his adult life? Phillips and Wendler write that

\begin{abstract}
We do not respect a competent 60 -year-old patient by basing treatment decisions on the values they endorsed when 30 years old. We respect them by treating them based on the values they presently endorse. Similarly, if a nowincompetent patient completed several conflicting advance directives while competent, we follow the one they most recently completed. ${ }^{2}$
\end{abstract}

It is, however, not immediately clear why we should regard an incompetent person's most recent competent self as equivalent to a competent person's present self. It seems that further argument is required here.

Perhaps one could defend Phillips and Wendler's view by noting that an incompetent person's most recent competent self will generally have stronger psychological connections to her present self than do her earlier selves. For example, her most recent competent self may still figure in her memories, whereas her earlier selves may not. Perhaps this suggests that the incompetent person's most recent competent self has greater authority over her present self than do her earlier selves.

However, it is hard to see how this appeal to psychological connectedness could justify setting aside the values of those earlier selves entirely. Psychological connectedness is a matter of degree, and if an incompetent patient's most recent competent self is somewhat psychologically connected to her current self, then it is likely that her earlier selves are also somewhat (though perhaps less) connected. This might seem to suggest that the values of those earlier selves should be given some (though perhaps less) weight in decisions about her current treatment.

Alternatively, Phillips and Wendler might argue that an incompetent patient's most recent competent self should be given precedence over earlier selves because people generally perfect their values over time. Thus, their last values formed while competent will typically be, in some sense, their truest or most authentic.

This may often be the case. However, there are reasons to doubt whether it will always be so. For instance, in many cases - especially in the presence of a gradually worsening neurological disorder, such as Alzheimer's disease-loss of competence is preceded by a period of reduced cognitive capacity. Though this loss of capacity is not yet sufficient to undermine competence, one might nevertheless suspect that it could alter the person's values in ways that we might think would make them less, rather than more, authentic.

\section{PETERSEN ON PROCREATIVE \\ BENEFICENCE}

Later in the issue, Thomas Søbirk Petersen discusses Julian Savulescu and Guy Kahane's well-known principle, procreative beneficence. ${ }^{3}$ According to this principle, prospective parents who are in a position to select between different possible future children have a significant moral reason to select the child whose life can be expected to go best. ${ }^{4}$ This may imply, for example, that in some cases parents undergoing in vitro fertilisation ought to employ pre-implantation genetic diagnosis to avoid having a child with a predisposition to genetic disease.

Petersen argues that, in using the phrase 'significant moral reason' [my emphasis], Savulescu and Kahane must be claiming that the reasons parents have to select the child with the best life are stronger than other reasons bearing on selection decisions, including reasons to benefit others. This, he suggests, entails that parents should be partial to their possible future children, giving more weight to their interests than to those of other, existing people. Suppose that prospective parents face a choice between having a child with the universal recipient blood type (best for the child, since it will be easier to find a donor if that child ever requires a blood transfusion) and having a child with a universal donor blood type (best for others, 
since any blood donated by that child later in life will have greater medical utility). ${ }^{5}$ On Petersen's interpretation, procreative beneficence implies that the wellbeing of the future child bears more powerfully on this decision than the wellbeing of any existing individual who stands to benefit from the existence of an additional universal donor. But Petersen argues that this commitment to partiality is not sufficiently motivated by Savulescu and Kahane. He also holds it to be inconsistent with common sense judgments about certain reproductive decisions.

\section{CAN 'PRE-PARENTAL' PARTIALITY BE JUSTIFIED?}

Regardless whether procreative beneficence indeed requires partiality, Petersen's question is an important one. Should prospective parents be partial towards their own possible future children? Should they engage in what we might call pre-parental partiality? The answer to this question will have implications not only for reproductive ethics but also more widely. May a couple planning to have a child permissibly invest all of their wealth into buying a large house that will provide an ideal environment for that child when they could instead divert some to other more needy children? This depends, in part, on how partial they ought to be to their future children.

Interestingly, many justifications for partiality towards existing children do not clearly support such pre-parental partiality. For instance, on some accounts, the justification for ordinary parental partiality derives from the presence of an intimate relationship between the parent and the child. ${ }^{6}$ But it is doubtful whether it is conceptually possible for a prospective parent to have an intimate relationship with her merely possible future child.

There is, then, interesting work to be done in elucidating the implications of the growing literature on parental partiality for the question whether and when prospective parents ought to engage in pre-parental partiality.

\section{KERRUISH AND MCMILLAN ON THE ASHLEY TREATMENT}

The present issue also includes an illuminating study of the so-called Ashley treatment. This treatment-named after the first patient to undergo it-involves the administration of hormones (and in some cases other interventions) intended to limit further growth of a severely disabled child. It has been controversial, in part because many (perhaps most) of the benefits of the intervention for the child who undergoes it are indirect, stemming from the way in which the treatment eases burdens for parents, and not from its direct biological effects.

Authors Nikky Kerruish and John McMillan report on an interview with the parents of a 6-year-old child who began the treatment a year previously. ${ }^{7}$ Their paper includes many interesting insights into what motivated the parents to seek the treatment, how they conceived of its purposes, and how they have experienced its effects.

Among the observations made by the parents is they did not, in their thinking about the treatment, clearly delineate their own interests from those of their child-they regarded these interests to be so intertwined that such a separation was not possible. This, Kerruish and McMillan seem tempted to suggest, may give us reasons to downplay the significance of concerns about some benefits to the child being 'merely indirect'.

\section{WHY DISCOUNT INDIRECT HEALTHCARE BENEFITS?}

Of course, even if parent and child interests could be separated, and were indeed separated by parents considering the Ashley treatment, there might be grounds for doubting whether indirectness of benefits really is a problem. Consider the following hypothetical case:
A couple have a child with an unusual and debilitating infectious disease. Anti-viral drugs can be used to significantly reduce the child's viral load, and thus her infectiousness to others, including the parents. In the absence of this treatment, the parents would need to take extensive measures to protect themselves against infection, and this would significantly impede their ability to interact intimately with their child. With the treatment, the parents can safely eschew these measures and interact with the child normally. The treatment has no direct biological benefit for the child, and comes with some side-effects. However it does significantly benefit the child overall, because of the greater parent-child intimacy that it enables.

This treatment will, I suspect, strike many as rather unproblematic. Yet its benefits for the child are wholly indirectthey are brought about by easing burdens on the parents. Reflecting on cases like this might thus lead us to speculate that the indirectness of many of the benefits brought about by the Ashley treatment is not significantly problematic, and that, if there are indeed sound ethical objections to the treatment, they must lie elsewhere.

\section{REFERENCES}

1 Phillips J, Wendler D. Clarifying substituted judgement: the endorsed life approach. J Med Ethics 2015;41: 723-30.

2 Phillips J, Wendler D. Clarifying substituted judgement: the endorsed life approach. J Med Ethics 2015;41: $723-30$.

3 Petersen TS. On the partiality of procreative beneficence: a critical note. J Med Ethics 2015;41: 771-4.

4 Savulescu J, Kahane G. The moral obligation to create children with the best chance of the best life. Bioethics 2009:23:274-90, p. 274.

5 The example comes from Elster J. Procreative Beneficence - Cui Bono? Bioethics 2011:25:482-88, p. 484

6 See, for example, Jeske D. Families, friends, and special obligations. Canadian Journal of Philosophy 1998;28:527-55

7 Kerruish N, McMillan JR. Parental reasoning about growth attenuation therapy: report of a single-case study. J Med Ethics 2015;41:745-9. 